\title{
TEACHING AND LEARNING OF INTEGERS USING HANDS-ON VERSUS VIRTUAL MANIPULATIVES
}

\author{
Goh Lin Sen ${ }^{1}$, KhairulAmilinTengah ${ }^{2}$, Masitah Shahrill ${ }^{3}$ andElvynna Leong ${ }^{4}$ \\ ${ }^{1}$ Raja IsteriPengiranAnakSaleha Secondary School, Ministry of Education, Brunei \\ ${ }^{2,3}$ Sultan HassanalBolkiah Institute of Education, Universiti Brunei Darussalam, Brunei \\ ${ }^{4}$ Faculty of Science, Universiti Brunei Darussalam, Brunei
}

\begin{abstract}
The purpose of this action research paper was to investigate the use of manipulatives in the teaching of addition and subtraction of integers. This research also looked at the impact of technology integration in the Mathematics classroom towards students' academic performance, students' motivation in learning integers, and students' attitude towards technology in Mathematics. The intervention lessons, which included the use of hands-on coloured counters and virtual manipulatives in the Gizmos application webpage, were carried out in two classes comprising 51 students in a secondary school in Brunei. This research adopted a quantitative approach of analysing participants' assessment scores, in addition to individual responses to questionnaires, and observational data collected during the interventions. Analysis of the result indicates that there is improvement in students' academic performance, which carries positive impact towards students' motivation, and students' attitude from both intervention methods. Another important finding of the study was, students that achieved higher assessment scores were more motivated and had a more positive attitude after taking part in the technology-enhanced lessons.
\end{abstract}

Keywords: Manipulatives, Gizmos Application, Motivation, Attitudes

\section{Introduction}

The world today is more competitive than ever.The skills considered noteworthy twenty years ago might not even be relevant today.Employers are continuously looking for "marketable" graduates that not just have the academic qualifications, but are also equipped with skills and qualities that meet the market needs or requirements of the industries.However, schools and universities are lagging behind in meeting these needs (Baharun and Suleiman, 2009). Morgan (1997) argued that there is gap between the knowledge, skills and qualities possessed by students and those expected by employers. Consequently, educators are highly depended on to bring out the best in their students. In 2009, Brunei's Ministry of Education implemented SPN 21, an acronym for Sistem Pendidikan Negara Abad ke-21 or the 21st Century National Education System (Ministry of Education, 2013). The main aim of revamping the national system is to restructure the foundation policy for learning and assessment in schools to align with the 21st century demands and needs (Ministry of Education, 2013).This signalled the desire of the Ministry of Education to upgrade the teaching and learning in schools to improve education achievement, and holistic development of individuals in Brunei.

The theory of experiential education stipulates that enhancement happen when students learn new knowledge through active engagement (Hartshorn and Boren, 1990). The use of manipulatives allow students learn to advance to abstract reasoning via concrete experiences (Reisman, 1982; Heddens, 1986; Ross and Kurtz, 1993).According to Stein and Bovalino (2001):

Manipulatives can be important tools in helping students to think and reason in more meaningful ways. By giving students concrete ways to compare and operate on quantities, such manipulatives as pattern blocks, tiles, and cubes can contribute to the development of well-grounded, interconnected understandings of mathematical ideas.

Teacher' role is important in designing manipulatives and assisting students in using them successfully. As useful manipulatives might be,researchers have found that teachers face hurdles in bridging that gap between the knowledge from the manipulatives, and math symbolisation and abstraction (Kamina and Iyer, 2009). Teachers

Corresponding Author:KhairulAmilin Tengah/ khairul.tengah@ubd.edu.bn

$3^{\text {rd }}$ International Conference on Education, 20-22 April 2017, Kuala Lumpur, Malaysia 
are unable to connect the concrete stage to the abstract stage and students often fail to apply the correct heuristic or learning strategies they acquired in attempting the problem-solvingtask (Hoy, 2008).

Coy (1997) suggested these conditions for successful transfer: (a) commonality between the topics, and (b) learner's ability to recognition these common elements. Students' learning can be greatly enhanced with proper use of manipulatives to assist the teaching of mathematics. Papert (1980) defined manipulatives asobjects to think with and allow the meaningful use of manipulatives into mathematics lessons to encourage easier grasp of concept by students to ensure effective learning to take place.

Joubert (2013) stated that there has been increase interest in integrating technology in the process of teaching and learning of mathematics.This is not surprising, as technology has become part-and-parcel of the everyday life of thenewer generations. This in-turn has created an opportunity and desire for a shift from a teacher-centred model education to a learning community model rich in the skill of technology use and information access (Rodriguez and Berryman, 2002). The use of technology in mathematics lessons has provided students to have positive attitudes, build confidence in their ability to do mathematics, construct mathematical knowledge, and visualise abstract mathematical concepts (Kersaint, 2007). Various types of technologycan be used as tools to enhance student-learning experiences in classrooms. Technology instruction such as computer-mediated learning replaces traditional exercises and worksheets, letting students solve problems at their own pace and giving them immediate feedback, both of which are invaluable in studying mathematics. Other technology uses include use of graphical calculators to assist students in graphs-heavy topics such as functions, and the use of videos or soft wares to explain certain mathematical concepts in classrooms.

On the other hand, teachers could analyse their students' performance in a quick and reliable way through technology. Traditional use of pen and paper marking is a long and tedious process and human error in marking is always an issue. Use of technology can eliminate these problems. In addition, with so many readily available interactive software online, feedback for each individual student could be immediate.

It is unfortunate to observe such utilisation of technology in mathematics classrooms in Brunei being very limited or sometimes not seen at all. Teachers still prefer traditional mathematics teaching, whereby a teacher demonstrates mathematical skills and procedures to students in a classroom setting, followed by students practicing and replicating what the teacher has demonstrated.However, this is not so effective when it comes to students who are less attentive in class and lacking motivation to study. Hence, it is essential to shift existingteacher-focused teaching strategies to more student-centred learning methodologies such as computermediated learning. Students using technology are more motivated, participated more, and are more likely to defend their answers in class (Souter, 2002). Whereas in classrooms where technology is being integrated, we still have to question whether the technology used is effective in student learning or not. Microsoft PowerPoint are popularly used to display slides of information, which students can easily obtained from their textbooks. Is this kind of technology enhancement different from the traditional "chalk and talk" teaching approach? It is important to have instructional strategies when integrating technology: one that takes into account students' readiness and expected achievement to allow an effective integration.

Fortunately, schools in Brunei have taken steps to increase effective usage of technology in mathematics classroom nation-wide. One of the ways the Ministry of Education (MOE) attempts to achieve the objectives of Sistem Pendidikan Negara Abad Ke-21 (SPN 21)is by using the 21st Century Learning Design (21 CLD), a global professional development program which provides practical frameworks and tools for teachers to incorporate into their lessons. 21CLD encourages teachers to integrate ICT into parts of their teaching.

\section{Purpose of Project}

This paper aims to examine the effect of replacing traditional teaching methods with a student-centred learning model in using manipulatives to deduce whether there is a positive impact on student academic achievement in mathematics. In addition, this paper also investigates the effects of technology on student performance, student motivation to learn and student attitude towards technology. In order to achieve this, the researcher will implement a teaching plan on the topic of addition and subtraction of integers in a Brunei school. 


\section{Research questions}

The research questions used to guide this research include:

1. How does the use of manipulatives affect student academic performance in addition and subtraction of integers?

2. How does technologyaffect student academic performance in addition and subtraction of integers in comparison to the hands-on manipulative model?

3. What is the general student attitude towards technology usage in the mathematics classroom?

4. How does technology affect student motivation to learn addition and subtraction of integers?

\section{Review of Literature}

\section{Integer Teaching Strategies}

The subject of integers is a very important part of the middle school mathematics curriculum as it symbolizes a move from concrete to abstract thinking (Lamb and Thanheiser, 2006). There are several methods or models invented to help assist students in learning and understanding the ideas or concept behind calculations involving integers. To name a few, money, number line, balloons and weights, and two-colour tiles (Cemen, 1993).

Whilst each of the models are useful to some extent, almost all of them have their own disadvantages. Cemen (1993) recommended the number line to teach the addition and subtraction of integers. She claimed that other models did not do a good job in the understanding of negatives and subtraction. The money model uses the concept of receiving and spending money, but when the starting value of money is negative, students have a hard time understanding 'negative money' (Cemen, 1993). The two-colour tiles model, similar to the counters model involved in this study, is helpful in showing addition and subtraction of integers, yet it is difficult to communicate the concept that subtracting a negative integer is the same as adding a positive integer. Cemen uses the number line method to distinguish between the rules of subtraction and rules of addition on a number line. The positive or negative sign of the number dictates which movement on the number line, while subtraction is demonstrated by using the action of "turning around". For example, when subtracting a negative number,it would require you turn around and then proceed backwards, which in this case is moving right in the positive direction on the number line (Cemen, 1993).

Lamb and Thanheiser (2006) created another approach to the understanding of addition and subtraction of integers. They created a software called 'Balloons and Weights', which is a technology-enhanced model of the paper and pencil version initially reported by Janvier (1983). Helium balloons represent positive integers, whereas weights represent the negative integers, in describing addition and subtraction of integers. The software illustrates positive numbers as a hot air balloon "going up" and negative numbers as weights "pulling down" the hot air balloon. So for instance, when there are more weights than balloons, the hot air balloon moves downwards, leaving the answer as negative. Depending on the question, subtraction is modelled as "removing" either the balloons or weights. Lamb and Thanheiser claimed that because of the pulling down direction effect of the weight and resulting final position, the rules associated with their actions are not as confusing as those of a typical horizontal number line. They added that the software affords animation that allows visualisation of what will happen to facilitates students' test conjectures.

Jennifer L. Miller conducted a study of teaching integer addition and subtraction using net worth (money) concept in 2013 (Miller, 2013). Her method centred on the concept of asset and debts that would result in net worth, and consisted of careful unit planning throughout seven days to teach students into understanding this method. Students were asked to compare net worth in the beginning, leading to modelling different scenarios using symbols, and finally asked to evaluate number sentences outside of any context. Miller claimed students understand that taking away debt is a good thing and will result in a positive effect on net worth. This proved that her curriculum allowed a clear understanding of the abstract concept of why subtracting a negative value creates a more positive answer; a concept which many other integer pedagogies break down and resulted in creating more confusion than clarity amongst students. She concluded that the idea of the effects of transactions 
on net worth proved to be one of the most powerful ideas in communicating operational integer concepts (Miller, 2013).

While many integer pedagogies exist, which best method is remains to be seen (Miller, 2013). For the purpose of this research, the chips/counter model was chosen as it achieved some minor success in the past during observation of several teachers in schoolsthroughout Brunei. It is also hoped that the combination of web-based instruction andpractice with the counters model will build a solid foundation for students in the understanding of addition and subtraction of integers.

\section{Effects of Technology on Mathematics Education}

Stipek (1996) wrote in his book that engaged students are more likely to approach tasks eagerly and to persist in the face of difficulty. In ouropinion, motivating students should be a priority for teachers as motivation leads to greater engagement. However, this can be a challenging task, especially in mathematics courses. Active learning isgenerally defined as any learning method that encourages engagement of students in process. Active students' engagement in the teaching and learning process will lead to increased student learning and persistence, better performance and enrich questioning exchange (Bonwell and Eison, 1991). Technology integration in mathematics lesson can encourage active participation of students in the classroom (Raines and Clark, 2011).

Souter (2002) researched on the effects of technology-enhanced algebra instruction on student academic performance, student motivation, and student attitude towards algebra. Her action research study, involving four teachers and five algebra classes, concluded that technology-integrated mathematics lesson has positive impact on students' achievement and motivation, foster positive student attitudes, and enhance student outcomes. In another study conducted by Fitzgerald (2015), she discovered educational benefits in terms of students' assessment scores when their face-to-face lessons are mirrored to the Cloud as lesson videos and note files for students to access outside their classrooms. When graphical calculators are usedas technological device to aid student learning, student achieved better performance and increased confidence in attempting problems (Quesada, 1996). Susskind (2005) claimed that presentation software such as Microsoft PowerPoint leads to increased student motivation and better positive attitudes when student attend lecture classes.

Within the past few decades, we have seen a rapid rise in the use of technology in classrooms in the developed world. National Council of Teachers of Mathematics, NCTM (2000) in their bookPrinciples and Standards for School Mathematicsstated that technology is essential in teaching and learning mathematics: it influences the mathematics that is taught and enhances students' learning (p. 24). They added that technology should be accessible to all students, but should not be used to replace conceptual understanding, computational fluency, or problem solving skills (NCTM, 2000, p. 6). When technological tools are available, students can focus on decision-making, reflection, reasoning and problem solving (NCTM, 2000, p. 24).

Mathematics classrooms uses a number of different technologies with varying degrees of success. Technology can refer to computerised instruction and practice, online videos or presentation software, graphical calculators and many more. Web-based instruction and practice will focused as the technology in this paper.

Numerous studies have shown that there is a positive impact on student academic achievements when webbased instruction and practice are used in mathematics classes. A reason of this is that the usage of this technological tool assists students in learning mathematics concepts. King (1997) meta-analysis investigation of computer-enhanced instruction on college level mathematics on thirty1986 to 1995 published studies revealed that there was positive influence on student achievement when computer technology was used and allowed in a classroom, lab setting or tests. He also found that the usage of computers in instruction and demonstrations was most beneficial to student learning. In a study conducted by Nguyen and Kulm in 2005 involving 95 students from two schools in southeast Texas, their quantitative data revealed that students'achievement was statistically higher in their post-tests after a web-based approach to instruction was done compared to those of normal pencil and paper teaching. Their results concluded that web-based instruction have positive effect on student-learning, aid in self-motivation in learning math and problem solving, and encourage students' independence to learning. 
In a similar study, Hodgeet al. (2009) investigation on 1394 college students concluded that students favour webbased homework as it increases their mathematical understanding more than conventional paper and pencil work. They also claimed that students were more motivated to complete their homework due to the immediate feedback they received. Mavrikis and Macioca (2003) stressed that immediate feedback is an advantage feature in web-based practice. Immediate feedback can help in building students' confidence, especially lowerachieving students. It encourages the students to do more practice and correct their own mistakes if they are unsure about a particular mathematics concept or procedure.

Research from both learning theory and classroom studies shows that using manipulatives to help teach mathematics can positively affect student learning (Sugiyama, 1987; Clements, 1999). Our paperfocused on the counters model to conclude whether there is any significant impact on student performance in a school in Brunei comprised of average to lower-achieving students. This paper also looked at the effects on added technology to enhance students' learning model further this study.

\section{Methodology}

A convenient sampling of 51 average to low achieving studentsfrom a local government co-ed school was involved in this study. The majority of the students are local Bruneians who come from nearby areas, comprising of just one racial group (Malay). This study sample of 22 males and 29 females from twoyear 7 classes: Class A - those taught using hands-on manipulatives then followed by virtual manipulatives; Class B those taught using only hands-on manipulatives. The age range of the sample was in between 11 and 13 years old.

Other teachers taught the participants addition and subtraction of integers using the number line model two weeks prior to this research. Pre-test, consisting of 15 questions on addition and subtraction of integers, were given to students prior to intervention lessons to determine baseline knowledge of participants in this area. Same questions, although reshuffled, were used as post-test at the end of the research study for comparison and analyses purposes. Students completed each test within thirty minutes.For Class A, post-testswere given to students both after the hands-on intervention lesson and after the virtual manipulative lessons.

In this research's intervention, manipulatives in the form of counters model was used to aid in students' learning of addition and subtraction of integers. Both groupswere introduced with this hands-on counter model. This was followed by a virtual manipulative lesson to determine the effects of technology on the teaching and learning of mathematics to just one of the group (Class A). The intervention in both classes focused on students' active learning and allowed the participants to arrive at their own conceptual understanding with minimal guidance of the content from the teacher. Table 1 indicates the summary of activities conducted in the intervention lessons.

Table 1Summary of the activities that incorporated during the study

\begin{tabular}{|c|c|c|}
\hline & Hands-on intervention lessons & Virtual intervention lessons \\
\hline $\begin{array}{l}\text { Assessment of prior } \\
\text { knowledge }\end{array}$ & Pre-test & Post-test 1 \\
\hline \begin{tabular}{l}
\multicolumn{3}{l}{ Intervention - } \\
1 st \& 2nd lessons \\
(Concrete
\end{tabular} & $\begin{array}{l}\text { 1. Exploration sheets given to } \\
\text { students. } \\
\text { 2. Red and yellow counters } \\
\text { introduced to students. Explain that } \\
\text { "zero pairing" is made up of one red } \\
\text { counter and one yellow counter (by } \\
\text { using the analogy of army men) } \\
\text { 3. Students practice on using the } \\
\text { counters to solve simple } \\
\text { mathematical problems. }\end{array}$ & $\begin{array}{l}\text { 1. Exploration sheets given to } \\
\text { students. } \\
\text { 2. Exploration sheet provides } \\
\text { systematic instruction to help student } \\
\text { explore the concept of counters } \\
\text { model. } \\
\text { 3. Student learning of the use of } \\
\text { counters to solve simple mathematical } \\
\text { problems in Gizmos. }\end{array}$ \\
\hline
\end{tabular}




\begin{tabular}{|c|c|c|}
\hline $\begin{array}{l}\text { Intervention - } \\
\text { 3rd \& 4th } \\
\text { (Abstract stage) }\end{array}$ & $\begin{array}{l}\text { Transition of the use of counters to } \\
\text { the more abstract stage of just using } \\
\text { mathematical symbols. } \\
\text { Includes the use of more challenging } \\
\text { problems (larger numbers) for } \\
\text { students to solve. }\end{array}$ & $\begin{array}{l}\text { Transition of the use of counters to the } \\
\text { more abstract stage of just using } \\
\text { mathematical symbols. } \\
\text { Includes the use of more challenging } \\
\text { problems (larger numbers) for } \\
\text { students to solve. }\end{array}$ \\
\hline $\begin{array}{l}\text { Assessment of effects of } \\
\text { the intervention }\end{array}$ & Post-test1 & Post-test2 \\
\hline
\end{tabular}

The materials that were used in this research study includedone hundred red counters and one hundred yellow counters, three sets of printed pre-test and post-test questions, three sets of student exploration sheets, two sets of printed surveys, an ICT lab with twenty personal computers, Gizmos online application from ExploreLearning. Any statistical analysis was carried out using SPSS software.

The student exploration sheets were designed separately for the hands-on lessons and the technology-enhanced lessons. Each set of exploration sheets hadsystematic instructions to guide the participants through the whole activity. There were questions on the exploration sheets with plenty of space for the participants to fill in.

There were two different surveys used at the end of this study: motivational survey and attitudinal survey. The motivational survey consisted of four questions to determine how motivated students were in learning integers, and whether the interventions that took place had any effects on their motivation. The attitudinal survey consisted of three questions that determined general student attitudes towards technology, and whether the interventions that took place had any effects on their attitudes towards technology. These two surveys both used a five-level Likert format, where the student participants have to indicate their responses by circling on a scale of 1 to 5 ( 1 = strongly disagree; $2=$ disagree; $3=$ neither agree or disagree; $4=$ agree; $5=$ strongly agree).

The research framework used to carry out this research can be summarised in figure 1.

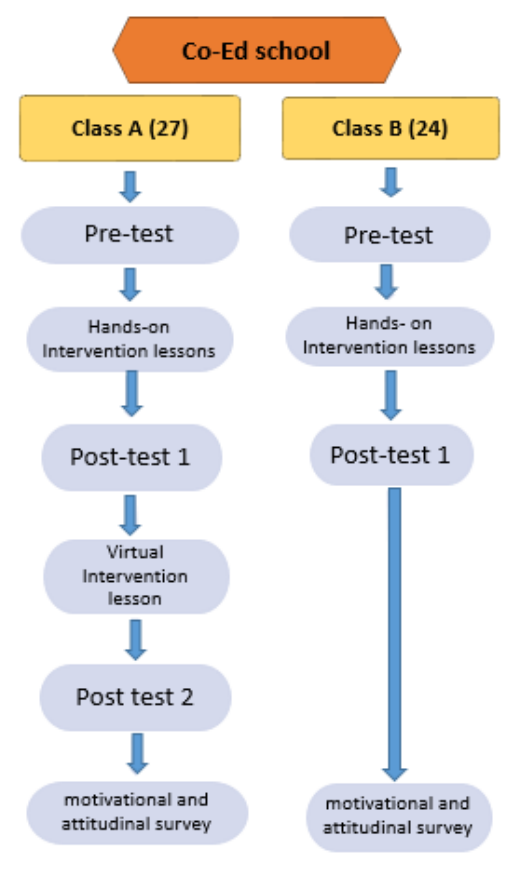

Figure 1Research framework used to carry out this study 
virtual manipulatives interventions on student performance.Each correct response in the assessment questions gets one mark, with a perfect score being 15 in each assessments. To compare the assessment scores of the twoclasses, SPSS softwarewas used to calculate the descriptive statistics and frequency of the descriptive data. A paired samplet-test used to compare the mean betweenpre-test and post-test1 results (for impact of hands-on intervention lesson), and to compare the mean between post-test 1 and post-test 2 (for impact of virtual intervention lesson). A p-value of less than 0.05 was accepted as significant. All statistical calculations were performed using Statistical Package for the Social Science (SPSS) software with the addition of UCCS (University of Colorado) website's effect size calculator to calculate the effect size statistic.

Likewise, the quantitative analysis of the surveys allowed the researcher to find out the level of student motivation to learn integers before and after the respective interventions and student attitude towards technology generally and student attitude towards technology usage in the mathematics classroom.

\section{Result}

\section{Statistical result}

Table 2 presents the mean scores and standard deviations achieved by Class A and Class B students in their respective pre-tests and post-tests. Mean was chosen to determine the average or "central" scores achieved by the students as a group. SD represents standard deviation, which is measures how spread out the scores were in the tests within that group.

Table 2Pre-test and Post-test Results

\begin{tabular}{lcccc}
\hline & \multicolumn{2}{c}{ Hands-on + Virtual (Class A) } & \multicolumn{2}{c}{ Hands-on (Class B) } \\
\cline { 2 - 5 } & Mean & SD & Mean & SD \\
\hline Pre-test scores & 7.11 & 3.00 & 7.38 & 1.91 \\
\hline Post-test 1 scores & 9.78 & 2.62 & 10.00 & 2.05 \\
\hline Post-test 2 scores & 10.59 & 2.58 & - & - \\
\hline$\%$ change & 48.95 & & 33.50 & \\
\hline
\end{tabular}

On first inspection, the result indicates that in both classes, there is an increase in mean value after the hands-on lesson intervention (increase of mean 2.67 for Class A and 2.62 for Class B), and for Class A, a further increase of post-test 2 mean score compared to post-test 1 (0.81) after the virtual intervention lesson. Further analysis was done to determine if these increases are statistically significant.

The result collected from the pre-tests and both post-tests were continuous in nature with no outliers in the data sets. These data were then checked whether they were normally distributed using SPSS.A Shapiro-Wilk's test ( $p>0.05$ ) and a visual inspection of their histograms, normal Q-Q plots and box plots showed that the pre-test scores were approximately normally distributed for both Class A and Class B, with a skewness of 0.289 $(\mathrm{SE}=0.448)$ and a kurtosis of $0.497(\mathrm{SE}=0.872)$ for Class $\mathrm{A}$ and a skewness of $0.477(\mathrm{SE}=0.472)$ and a kurtosis of $-0.020(\mathrm{SE}=0.918)$ for Class $\mathrm{B}$.

Another Shapiro-Wilk's test $(\mathrm{p}>0.05)$ and a visual inspection of their histograms, normal Q-Q plots and box plots showed that Post-test1scores were approximately normally distributed for both Class A and Class B, with a skewness of $0.123(\mathrm{SE}=0.448$ ) and a kurtosis of -0.221 ( $\mathrm{SE}=0.872$ ) for Class $\mathrm{A}$ and a skewness of -0.094 $(\mathrm{SE}=0.472)$ and a kurtosis of $-0.490(\mathrm{SE}=0.918)$ for Class $\mathrm{B}$.

Finally, a Shapiro-Wilk's test ( $\mathrm{p}>0.05)$ and a visual inspection of its histogram, normal Q-Q plot and box plot showed that Post-test 2 scores were approximately normally distributed for Class A, with a skewness of -0.108 $(\mathrm{SE}=0.448)$ and a kurtosis of $-0.747(\mathrm{SE}=0.872)$. 
Since all the pre-test and both post-test scores were approximately normally distributed and fulfilling the required conditions, paired samples t-test were conducted to determine whether there were significant differences between them.

First, paired sample t-test to compare student academic performance in the pre-test scores and post-test scores of Class A resulted in a significant increaseof test scores from pre-test $(\mathrm{M}=7.11, \mathrm{SD}=3.00)$ to post-test1 $(\mathrm{M}=9.78$, $\mathrm{SD}=2.62), \mathrm{t}(26)=-4.966, \mathrm{p}<0.000$ (two-tailed). The mean increase in the integer test scores was 2.67 with a $95 \%$ confidence interval ranging from -3.76 to -1.57 . The eta-squared statistic $(0.49)$ indicated a large effect size.This resultgives evidence that there was improvement in student academic performance in Class Aresulting in the usehands-on manipulatives in the addition and subtraction of integer lesson.

A paired sample t-test of Class B to compare student academic performance between the pre-test scores and post-test scores resulted in a significant increase of scores from pre-test $(\mathrm{M}=7.38, \mathrm{SD}=1.91)$ to post-test $1(\mathrm{M}$ $=10.0, \mathrm{SD}=2.05), \mathrm{t}(23)=-5.938, \mathrm{p}<0.000$ (two-tailed). The mean increase in integer test scores was 2.62 with a $95 \%$ confidence interval ranging from -3.60 to -1.74 . The eta-squared statistic ( 0.61$)$ indicated a large effect size. This result suggests that there was improvement in student academic performance in Class B after the teacher taught the topic using only hands-on manipulatives, which further support result from Class A. Both these results are evidence in proving that using hands-on manipulative have a positive significant impact on the performance of students in the teaching and learning of addition and subtraction of algebra.

Another paired sample t-test to compare the Post-test2 scores with Post-test1 scores in Class A resulted in a significant increase inmeanscoresfromPost-test $1(\mathrm{M}=9.78, \mathrm{SD}=2.62)$ toPost-test2 $(\mathrm{M}=10.59, \mathrm{SD}=2.58), \mathrm{t}(26)=-$ $3.698, \mathrm{p}<0.001$ (two-tailed). The mean increase in the integer test scores was 0.815 with a $95 \%$ confidence interval ranging from -1.27 to -0.36 . The eta-squaredstatistic (0.34) indicated a large effect size. This resultindicates that there was further improvement in student academic performance in Class A after the teacher taught the topic using virtual manipulatives, suggesting that the use of virtual manipulatives do have significant impact on the performance of students in these types of integer lesson

\section{Students' Motivation to Learn Algebra}

The motivational survey consisted of four five-level Likert questions, where the participants had to indicate their response by circling on a scale of 1 to 5: (1) Strongly disagree; (2) Disagree; (3) Neither agree nor disagree; (4) Agree; (5) Strongly agree.

Table 3Students' responses of their motivation in integers and in using technology in integers

\begin{tabular}{llcccc}
\hline \multirow{2}{*}{ Questions } & & \multicolumn{2}{c}{ Class A } & \multicolumn{2}{c}{ Class B } \\
\cline { 3 - 6 } & Mode & Frequency & Mode & Frequency \\
\hline 1. Motivated to learn integers & 3 & 14 & 4 & 15 \\
\hline $\begin{array}{l}\text { 2. Technology made/would } \\
\text { them more motivated }\end{array}$ & make & 4 & 17 & 4 & 18 \\
\hline 3. Participate in integers & 2 & 11 & 3 & 12 \\
\hline $\begin{array}{l}\text { 4. Technology made/would } \\
\text { them participate more }\end{array}$ & make & 4 & 19 & 4 & 16 \\
\hline
\end{tabular}

Table 3 presents the results of the survey where students were asked about their motivation in learning integers.Modewas chosen to determine the largest number of responses provided by the participants in each survey question.

When the participants were asked about their motivation to learn algebra, 14 out of 27 students from Class Aresponded with a score of 3 while 15 out of 24 students from Class Bresponded with a score of 4 . As a group, participants are inclined to agree that they are motivated to learn algebra. When asked whether technology made or would make them more motivated in learning algebra, 17 students from Class A responded with a score of 4and18 students from Class B responded with a score of 4 as well, indicating that they agree (to almost strongly agree) that the use of technology will motivate the learning of algebra. 
The survey also included questions to determine the participation rate of participants during the study. When asked whether they participated in integers before the intervention, 11 students from Class A responded with a score of 2 while 12 students from Class B responded with a score of 3. 19 participants fromClass A responded with a score of 4 when asked whether technology made/would make them participate more in class, while 16 Class B participants responded with a score of 4 as well. This suggested that students from both classes were more likely to claim that technology made them more motivated to learn integers and technology made them participate more in integer classes, despite Class B not being involved in virtual manipulative lesson in this research.

It was observed that during the intervention lessons, students participated more in class by asking more questions during the virtual manipulative lesson as compared to the hands-on lesson. The students who used technology were also more confident in their answers when being asked questions by the teacher. The ease of usage and better visual explanation provided by the Gizmos application as compared to the hands-on model might have significant effect on this observation. It was also discovered that the students were less likely distracted in the virtual lesson, as most of them were keen to learn using the application, compared to hands-on activity. These observations supports result from questionnaire that claim that technology-enhanced students are more motivated and participate more in the classroom.

The results collected from Class B supported this view. More than half of the Class B students agreed that technology would give them more motivation and they would participate more in the classroom if technology is added. Students from Class B claimed to be more motivated to learn integers if technology is added considering that they were not exposed to the virtual manipulatives lesson. It would be interesting to see the response of these students if they had the chance to experience the technology-enhanced lessons like Class A did.

\section{Students' Attitude towards Technology}

The attitudinal survey consisted of three five-level Likert questions, where the participants had to indicate their response by circling on a scale of 1 to 5: (1) Strongly disagree; (2) Disagree; (3) Neither agree nor disagree; (4) Agree; (5) Strongly agree.

Table 4Students' responses of their attitude towards technology

\begin{tabular}{llcccc}
\hline \multicolumn{2}{c}{ Questions } & \multicolumn{2}{c}{ Class A } & \multicolumn{2}{c}{ Class B } \\
\cline { 3 - 6 } & & Mode & Frequency & Mode & Frequency \\
\hline 1. & $\begin{array}{l}\text { Enjoy/would enjoy using } \\
\text { technology }\end{array}$ & 4 & 18 & 4 & 19 \\
\hline $\begin{array}{l}\text { Technology makes/would make } \\
\text { mathematics easier to learn }\end{array}$ & 5 & 15 & 3 & 15 \\
\hline 3. & $\begin{array}{l}\text { Use technology frequently in } \\
\text { everyday life }\end{array}$ & 4 & 18 & 5 & 15 \\
\hline
\end{tabular}

Table 4 presents the result of the survey where students were asked about their attitude towards technology. When students were asked whether they enjoyed or would enjoy using technology in mathematics classroom, both Class A and Class B students responded with a mode of 4, indicating agreement.

When asked whether technology made or would make mathematics easier to learn, 15 out of 27 from Class A students responded with a score of 5 whereas 15 out of 24 students from Class B responded with a score of 3 . This difference in answer may be related to their recent experience, or lack of, with technology during the intervention lesson. With Class A having been involved with technology-assisted learning in the virtual manipulation, they strongly agree with the statement that technology makes mathematics easier to learn by recent first-hand experience. In the case of Class $\mathrm{B}$, their neither agree nor disagree might possible be contribute to the fact some might not have experience learning maths via technology, including in this research process. 
Finally, 18 Class A students responded with a score of 4 while 15 Class Bstudents responded with a score of 5 when asked about whether they use technology frequently in their everyday lives, indicating that they strongly agree that technology is frequently used in students' everyday life. Majority of students from both classrooms claimed to use technology frequently in their everyday lives. Perhaps, the similarities in student attitude towards technology in mathematics education relate to the current generation's positive attitude towards technology in their daily lives.

\section{Conclusion}

The implication of this study is that the use of manipulatives has a significant positive effect on student academic achievement in algebra lesson. This study also indicated that the integration of technology into the mathematics classroom could further increase student academic achievement, improve student motivation and foster positive student attitudes in the mathematics subject. The research also found that the hands-on counters model helped students in the learning of addition and subtraction of integers. Careful choice of the right technologies can help students visualise key concepts with better ease, and in some cases, can provide better explanations than most traditional vocal inputs from teachers.

On the other hand, the positive results of this research demonstrated that the counters model remained a fine manipulative model within other existing integer pedagogies in tackling the topic of addition and subtraction of integers. The lower pre-test scores achieved by participants in this study suggested that the number line model used by other teachers before the intervention may possible be less effective than the counters model. Further research in the future in this subject area can take into consideration of other integer pedagogies mentioned in the literature review but not used in this study.

The study also concluded that technology-enhanced students have more motivation to learn mathematics in class in comparison to hands-on students. The results coincided with other studies that involved technology enhancement in mathematics classrooms and reported positive outcomes (Souter, 2002; Susskind, 2005; Nguyen and Kulm, 2005; Fitzgerald, 2015). Even though many teachers might find challenges in integrating technology into their teaching, they have to comprehend that creative and constructive technology integration provides an eye-opening experience to students, which can be invaluable in their future. Other studies have investigated the reasons mathematics teachers rarely use technology in their teaching and found that it was mostly related to their beliefs on mathematics teaching and learning and their existing pedagogies (Norton et al. 2000). With current emphasis on technology integration in SPN21, educators in this country are beginning to undergo training on technology usage in classrooms. Teacher technology training can be a good start to increase the integration of technology in the mathematics classroom.

\section{References}

Baharun, R., and Suleiman, E. S., 2009, Theemployers' perceptions of what makes graduates marketable. Academia. edu, pp.1-17.

Bonwell, C. C., and Eison, J. A., 1991, Active Learning: Creating Excitement in the Classroom. 1991 ASHEERIC Higher Education Reports. ERIC Clearinghouse on Higher Education, The George Washington University, One Dupont Circle, Suite 630, Washington, DC 20036-1183.

Cemen, P. B., 1993, Teacher to teacher: adding and subtracting integers on the number line. Arithmetic Teacher, 40(7), 388-390.

Clements, D. H., Swaminathan, S., Hannibal, M. A. Z., and Sarama, J., 1999, Young children's concepts of shape. Journal for Research in Mathematics Education, 192-212.

Coy, W., 1997. Defining discipline. In Foundations of Computer Science (pp. 21-35). Springer Berlin/Heidelberg. 
Fitzgerald, R. J. E., 2015, Mirroring math lessons to the cloud: an online technology intervention case study. InSight: Rivier Academic Journal, 11(1).

Hartshorn, R., and Boren, S., 1990, Experiential Learning of Mathematics: Using Manipulatives. ERIC Digest. Heddens, J.W., 1986,Bridging the gap between the concrete and the abstract. Arithmetic Teacher, 33(6), 14-17.

Hodge, A., Richardson, J. C., and York, C. S., 2009, The impact of a web-based homework tool in university algebra courses on student learning and strategies. Journal of Online Learning and Teaching, 5(4), 619-929.

Hoy, A.W., 2008, What motivates teachers? Important work on a complex question. Learning and Instruction, 18(5), pp.492-498.

Janvier, C., 1983, The understanding of directed number. In J. C. Bergeron \& N. Herscovics (Eds.), Proceedings of the Fifth Annual Meeting of the North American Chapter of the International Group for the Psychology of Mathematics Education, Vol. 2, pp. 295-301. Montreal: Universiti de MontrPal, Faculti de Sciences de 1'Education.

Joubert, M., 2013, Using digital technologies in mathematics teaching: developing an understanding of the landscape using three "grand challenge" themes. Educational studies in mathematics, 82(3), 341-359.

Kamina, P., and Iyer, N. N., 2009, From concrete to abstract: Teaching for transfer of learning when using manipulatives. Date of access: 10/11/2015. http://digitalcommons.uconn.edu/nera_2009/6

Kersaint, G., 2007, Toward technology integration in mathematics education: A technology-integration course planning assignment. Contemporary Issues in Technology and Teacher Education, 7(4), 256-278.

King, H. J., 1997. Effects of computer-enhanced instruction in college-level mathematics as determined by a meta-analysis (pp. 1-187).

Lamb, L. C., and Thanheiser, E., 2006, Understanding integers: using balloons and weights software. Algebraic Thinking, 2, 163-164.

Mavrikis, M., and Maciocia, A., 2003, Wallis: a web-based ILE for science and engineering students studying mathematics. In Workshop of Advanced Technology for Mathematics Education in the 11th International Conference on Artificial Intelligence in Education, pp. 505-512.

Miller, J. L., 2013, A Curriculum Study: Teaching Integer Addition and Subtraction Using a Net Worth Concept. Education and Human Development Master's Theses. Paper 366.

Ministry of Education, 2013, The National Education System for the $21^{\text {st }}$ Century: SPN21(Revised ed.) (Berakas: Ministry of Education).

Morgan, G. J., 1997, Communication skills required by accounting graduates: practitioner and academic perceptions, Accounting Education, 6(2), 93-107.

National Council of Teachers of Mathematics, NCTM, 2000, Principals and Standards for School Mathematics. Reston, VA: Author.

Nguyen, D. M., and Kulm, G., 2005, Using web-based practice to enhance mathematics learning and achievement. Journal of Interactive Online Learning, 3(3), 1-16.

Norton, S., McRobbie, C. J. and Cooper, T. J., 2000. Exploring secondary mathematics teachers' reasons for not using computers in their teaching: Five case studies. Journal of Research on Computing in education, 33(1), pp.87-109.

Papert, S., 1980, Mindstorms: children, computers, and powerful ideas. Basic Books, Inc.. 
Quesada, A. R., 1996, On the impact of the first generation of graphing calculators on the mathematics curriculum at the secondary level. In P. Gomez \& B. Waits (Eds.), Roles of Calculators in the Classroom (pp. 143-163). Retrieved from http://ued.uniandes.edu.co/ued/servidor/em/recinf/t g18/ArchivosPDF/ Quesada.pdf

Raines, J. M., and Clark, L. M., 2011, A brief overview on using technology to engage students in mathematics. Current Issues in Education, 14(2).

Reisman, F. K., 1982, A Guide to the Diagnostic Teaching of Arithmetic (Columbus, Ohio: Charles E. Merrill).

Rodriguez, A. J. and Berryman, C., 2002, Using sociotransformative constructivism to teach for understanding in diverse classrooms: A beginning teacher's journey. American Educational Research Journal, 39(4), 10171045.

Ross, R. and Kurtz, R., 1993, Making manipulatives work: A strategy for success. Arithmetic teacher, 40(5), $254-258$.

Souter, M. T., 2002, Integrating technology into the mathematics classroom: an action research study. Action Research Exchange, 1(1), 1-11.

Stein, M. K., and Bovalino, J. W., 2001, Manipulatives: one piece of the puzzle. Mathematics Teaching in the Middle School, 6(6), 356.

Stipek, D. J., 1996, Motivation and instruction. Handbook of Educational Psychology, 85-113.

Sugiyama, Y., 1987, Comparison of word problems in textbooks between Japan and the U. S. In J.P. Becker, and T. Miwa (Eds.), Proceedings of U.S. - Japan Seminar on Problem Solving. Carbondale, IL: Board of Trustees, Southern University.

Susskind, J. E., 2005, PowerPoint's power in the classroom: enhancing students' self-efficacy and attitudes. Computers \& Education, 45(2), 203-215. 